\title{
Oxygen redox activity through a reductive coupling mechanism in the P3-type nickel-doped sodium
}

\section{manganese oxide}

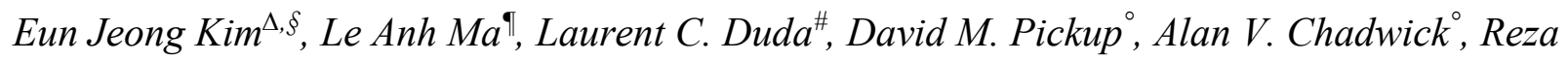
Younesi $^{\S}$, John T.S. Irvine ${ }^{\Delta}$, A. Robert Armstrong ${ }^{\Lambda, \S, *}$

${ }^{\Delta}$ School of Chemistry, University of St Andrews, St Andrews, Fife, KY16 9ST, United Kingdom

${ }^{\S}$ ALISTORE-ERI, 80039, Amiens Cedex, France

『Ångström Advanced Battery Centre, Department of Chemistry Ångström Laboratory, Uppsala University, Uppsala, SE-75121, Sweden

\#Department of Physics and Astronomy, Division of Molecular and Condensed Matter Physics, Uppsala University, Uppsala, S-75120, Sweden

'School of Physical Sciences, University of Kent, Canterbury, Kent CT2 7NH, United Kingdom

*ara@st-andrews.ac.uk

Sodium ion batteries, layered oxides, anion redox, P3 structure, reductive coupling mechanism, resonant inelastic X-ray scattering 


\section{ABSTRACT}

Increasing dependence on rechargeable batteries for energy storage calls for the improvement of energy density of batteries. Towards this goal, introduction of positive electrode materials with high voltage and/or high capacity is in high demand. The use of oxygen chemistry in lithium and sodium layered oxides has been of interest to achieve high capacity. Nevertheless, a complete understanding of oxygen-based redox processes remains elusive especially in sodium ion batteries. Herein, a novel P3-type $\mathrm{Na}_{0.67} \mathrm{Ni}_{0.2} \mathrm{Mn}_{0.8} \mathrm{O}_{2}$, synthesized at low temperature, exhibits oxygen redox activity in high potentials. Characterization using a range of spectroscopic techniques reveals the anionic redox activity is stabilized by the reduction of $\mathrm{Ni}$ owing to the strong $\mathrm{Ni} 3 \mathrm{~d}-\mathrm{O} 2 \mathrm{p}$ hybridization states created during charge. This observation suggests that different route of oxygen redox processes occur in $\mathrm{P} 3$ structure materials, which can lead to the exploration of oxygen redox chemistry for further development in rechargeable batteries.

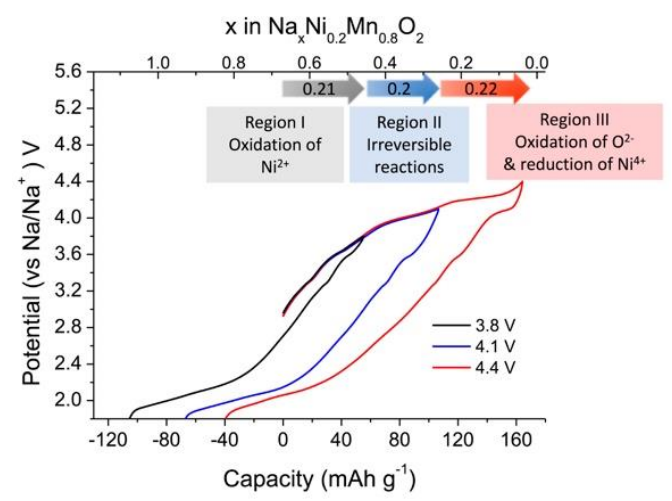




\section{Introduction}

Rechargeable batteries represent a potential solution to deal with the growth of energy demand without increasing carbon footprint. The integration of lithium ion batteries (LIBs) with intermittent renewable energy sources is an excellent technology for a sustainable planet. ${ }^{1}$ One of the key requirements for batteries in large-scale energy storage systems is low cost, including raw materials, production and installation of the batteries. In this respect, sodium ion batteries (SIBs) represent a promising alternative system to LIBs due to their competitive cost benefit and abundant resource supply.

Recently the use of cumulative cation and anion redox reactions has become a potential strategy to enhance the capacity of Li-rich layered oxides and extensive studies have been carried out to establish the mechanism of oxygen redox processes in LIBs. The knowledge gained from LIB research has been translated to SIBs and several studies on P2-type sodium manganese based oxides have shown the participation of oxygen ions in the redox processes. ${ }^{2-8}$ Oxygen redox has been also revealed in P3-type sodium manganese based oxides which are partially doped with electrochemically inactive elements such as lithium ${ }^{9,10}$ and magnesium. ${ }^{11}$ In addition, inherent vacancies in the transition metal layers have been shown to be an important source to permit reversible oxygen redox in $\mathrm{Na}_{2} \mathrm{Mn}_{3} \mathrm{O}_{7}$ retaining its rigid layered structure. ${ }^{12,13}$

As reported in the Li-rich layered oxides, the nature of the transition metals is important to trigger oxygen redox which stems from the hybridized character of oxygen with transition metals and/or formation of oxygen holes in a given structure. ${ }^{14}$ Similarly, various dopants in manganese sites have been extensively studied in the P2 structure compounds to understand the mechanism of charge compensation. ${ }^{2-8}$ In particular, electrochemically inactive dopants permit stable oxygen 
redox activated via the formation of oxygen holes or the strong hybridization between dopant and oxygen in P2-type $\mathrm{Na}_{2 / 3} \mathrm{Mg}_{0.28} \mathrm{Mn}_{0.72} \mathrm{O}_{2}{ }^{8}$ and $\mathrm{P} 2$-type $\mathrm{Na}_{2 / 3} \mathrm{Zn}_{2 / 9} \mathrm{Mn}_{7 / 9} \mathrm{O}_{2},{ }^{7}$ respectively. Additionally, the substitution of spectator ions for manganese suppresses several structural transitions and Jahn-Teller distortion during cycling, leading to the enhancement of cycling performance., ${ }^{4,5,15}$ In order to compensate for the decrease in initial capacity owing to electrochemically inert dopants, substitution of nickel for manganese has been explored via the $\mathrm{Ni}^{2+} / \mathrm{Ni}^{4+}$ redox couple in the P2-type materials. ${ }^{16-23}$

Variation in the oxygen stacking (ABBA and ABBCCA in P2 and P3 structure, respectively) may lead to significant differences in electrochemical properties and P3-type sodium manganese oxides are more environmentally friendly due to the lower sintering temperature than P2-type equivalents, it is therefore of interest to investigate the substitution of nickel for manganese in P3-type sodium manganese oxide to raise its capacity via the $\mathrm{Ni}^{2+} / \mathrm{Ni}^{4+}$ redox couple and possible oxygen redox, as well as to understand the effect of an electrochemically active dopant on oxygen redox.

Herein, we report on the synthesis and characterization of the novel P3-type $\mathrm{Na}_{0.67} \mathrm{Ni}_{0.2} \mathrm{Mn}_{0.8} \mathrm{O}_{2}$. The abnormally high capacity observed on the first charge is thoroughly investigated using a range of spectroscopic techniques. The participation of oxygen ions in the initial charge compensation mechanism is proposed.

\section{Results and discussion}

A fitted powder neutron diffraction (PND) pattern for as-synthesized $\mathrm{Na}_{0.67} \mathrm{Ni}_{0.2} \mathrm{Mn}_{0.8} \mathrm{O}_{2}$ is shown in Figure 1a and refined parameters are given in Table S1. Major Bragg diffraction peaks can be indexed on the $\mathrm{P} 3$ structure model (space group $R 3 \mathrm{~m}$ ), where Na ions occupy trigonal prismatic sites while $\mathrm{Ni}$ and $\mathrm{Mn}$ are located in the octahedral sites in a hexagonal unit cell with ABBCCA 
oxygen stacking. Additional peaks at around 2.1 and $1.47 \AA$ are assigned to $\mathrm{NiO}$ as an impurity phase ( $2 \%$ ), which often observed in nickel containing sodium transition metal oxides. ${ }^{21,24-26}$ The refined site occupancies of transition metals and sodium agree with the values derived from inductively coupled plasma optical emission spectroscopy (ICP-OES). The morphology of assynthesized $\mathrm{Na}_{0.67} \mathrm{Ni}_{0.2} \mathrm{Mn}_{0.8} \mathrm{O}_{2}$, shows primary particles around $100 \mathrm{~nm}$ fused together as shown in Figure 1b. The stoichiometry of the as-synthesized compound was determined to be $\mathrm{Na}_{0.6} \mathrm{Ni}_{0.18} \mathrm{Mn}_{0.8} \mathrm{O}_{2}$ (normalized to $\mathrm{Mn}$ ) by ICP-OES. 

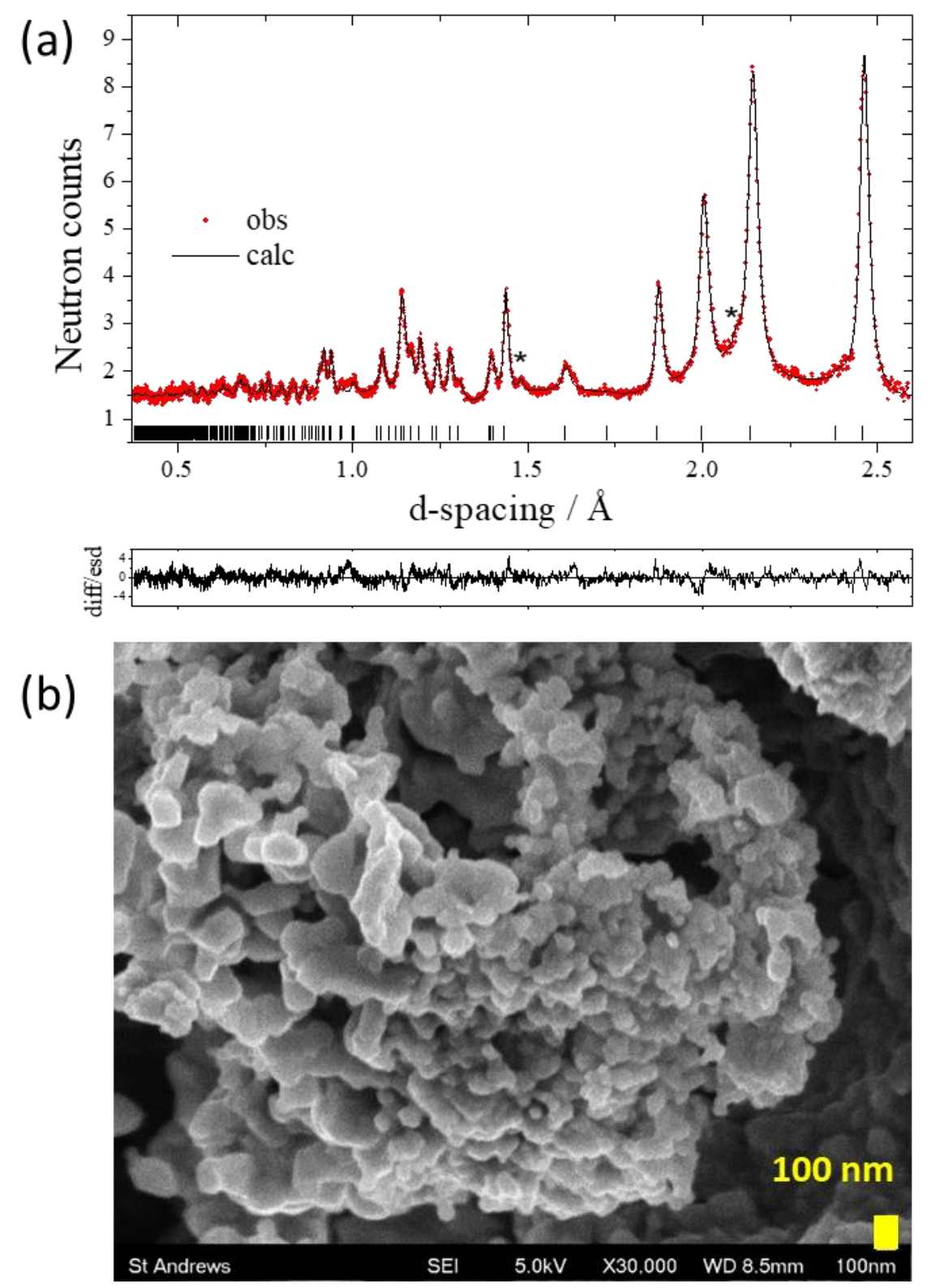

Figure 1. (a) Profile fit for $\mathrm{Na}_{0.67} \mathrm{Ni}_{0.2} \mathrm{Mn}_{0.8} \mathrm{O}_{2}$ obtained on bank $5\left(90^{\circ}\right)$ on the GEM diffractometer at ISIS. Observed data points are shown in red, with fitted profile in black. Tick marks indicate allowed reflections for the P3 phase. Asterisks indicate main peaks of NiO. (b) SEM image of as-synthesized $\mathrm{Na}_{0.67} \mathrm{Ni}_{0.2} \mathrm{Mn}_{0.8} \mathrm{O}_{2}$. 
The assembled coin cells with $\mathrm{Na}_{0.67} \mathrm{Ni}_{0.2} \mathrm{Mn}_{0.8} \mathrm{O}_{2}$ as the active material were cycled galvanostatically over three different voltage windows at a current rate of $10 \mathrm{~mA} \mathrm{~g}^{-1}$. As shown in Figure $2 \mathrm{a}$ the material cycled between 1.8 and $3.8 \mathrm{~V}$ delivers a first discharge capacity of $150 \mathrm{mAh} \mathrm{g}^{-1}$ and maintains $93 \%$ of its initial capacity after 25 cycles. When $\mathrm{Na}_{0.67} \mathrm{Ni}_{0.2} \mathrm{Mnn}_{0.8} \mathrm{O}_{2}$ is charged to $4.1 \mathrm{~V}$, a higher initial discharge capacity is delivered $\left(174 \mathrm{mAh} \mathrm{g}^{-1}\right)$ at the expense of cycling stability (capacity retention of $83 \%$ over 25 cycles). This trend continues in the widest voltage window (1.8-4.4 V) with an initial discharge capacity of $204 \mathrm{mAh} \mathrm{g}^{-1}$ albeit with capacity retention of $49 \%$ after 25 cycles. These results are analogous to $\mathrm{P} 2$-type $\mathrm{Na}_{2 / 3} \mathrm{Ni}_{1 / 3} \mathrm{Mn}_{2 / 3} \mathrm{O}_{2}$ whose cycle life is shortened when the material is charged over $4.0 \mathrm{~V}$ due to the poorly reversible phase transition to the $\mathrm{O} 2$ structure. ${ }^{17,18}$ Interestingly, the first charge capacity delivered from the sample charged to either 4.1 or $4.4 \mathrm{~V}$ is higher than the value expected solely from the $\mathrm{Ni}^{2+} / \mathrm{Ni}^{4+}$ redox reaction (94 $\mathrm{mAh} \mathrm{g}^{-1}$ ), assuming the $\mathrm{Mn}$ remains tetravalent during charging. The excess charge capacity on the first cycle will be further discussed later.

As shown in the differential capacity versus voltage $(\mathrm{dQ} / \mathrm{dV})$ plots, the material cycled in the voltage range 1.8-3.8 $\mathrm{V}$ reveals reversible reactions at ca. 1.95, 2.15, 3.27 and 3.57 $\mathrm{V}$ (Figure 2b). When the sample is cycled between 1.8-4.1 V (Figure 2c), an irreversible oxidation peak at $4.0 \mathrm{~V}$ is observed on the first cycle while the four redox couples below $3.8 \mathrm{~V}$ are reversible. The irreversible peak could be attributed to the structural change associated with significant crystallinity loss as shown in ex-situ PND patterns (Figure S1). When the sample is further charged to $4.4 \mathrm{~V}$, new oxidation and reduction peaks appear at ca. 4.2 and $4.1 \mathrm{~V}$, respectively (Figure 2d). The redox process at the highest voltage weakens on extended cycling accompanied by decreased redox reactions taking place below $3.8 \mathrm{~V}$, resulting in capacity fade. Cyclic voltammograms were collected by applying a progressively higher positive potential with a scan rate $50 \mu \mathrm{V} \mathrm{s}^{-1}$ from 
$\mathrm{OCV}$ to the upper cut-off voltage of $4.4 \mathrm{~V}$ with a voltage step $0.2 \mathrm{~V}$, fixing the lower cut-off voltage at 1.8 V. As revealed in Figure 2e, four oxidation peaks are compensated by four reduction peaks in a reversible manner until the upper cut-off voltage reaches $4.0 \mathrm{~V}$. When the positive potential is extended to $4.2 \mathrm{~V}$, a new oxidation peak appears without any corresponding reduction peaks on the following negative potential sweep. On the subsequent cycle, an additional oxidation peak appears at $4.25 \mathrm{~V}$ that is coupled to a reduction peak at $4.0 \mathrm{~V}$. The irreversible peak at $4.0 \mathrm{~V}$ and the oxidation peak at $4.25 \mathrm{~V}$ are clearly separated at a slower scan rate $30 \mu \mathrm{V} \mathrm{s}^{-1}$ as shown in Figure S2. Given that $\mathrm{Na}_{0.67} \mathrm{Ni}_{0.2} \mathrm{Mn}_{0.8} \mathrm{O}_{2}$ delivers significantly higher first charge capacity than that theoretically expected after charging to $4.4 \mathrm{~V}$ and large hysteresis is found in the sequential voltammograms, it is reasonable to propose the participation of oxygen anions in the redox processes of $\mathrm{Na}_{0.67} \mathrm{Ni}_{0.2} \mathrm{Mn}_{0.8} \mathrm{O}_{2}$. 

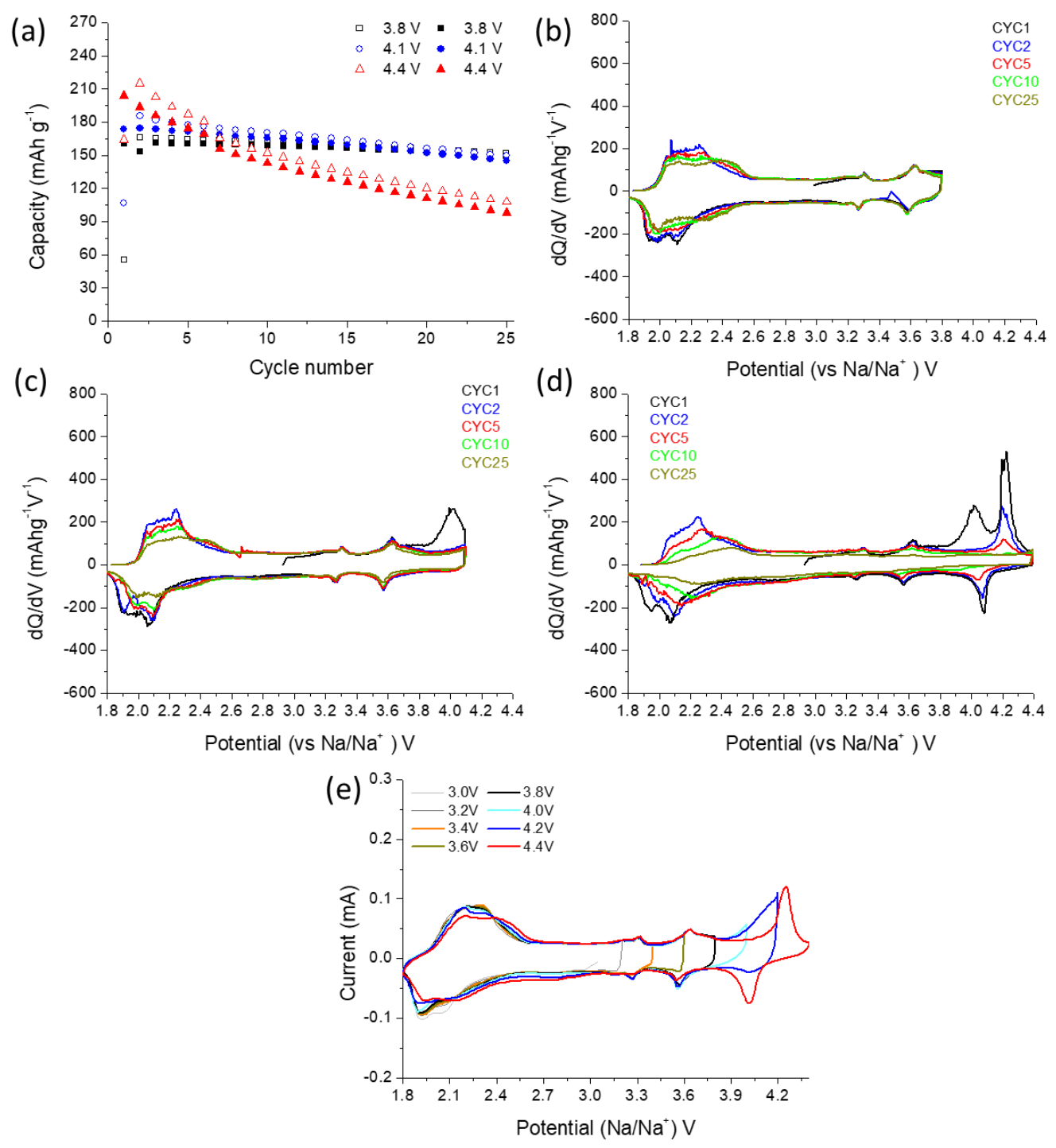

Figure 2. (a) Galvanostatic cycling performance of $\mathrm{Na}_{0.67} \mathrm{Ni}_{0.2} \mathrm{Mn}_{0.8} \mathrm{O}_{2}$ cycled at $30{ }^{\circ} \mathrm{C}$ in the voltage range 1.8-3.8 $\mathrm{V}$ (black), 1.8-4.1 $\mathrm{V}$ (blue) and 1.8-4.4 $\mathrm{V}$ (red) at a rate of $10 \mathrm{~mA} \mathrm{~g}^{-1}$. Empty and full symbols represent charge and discharge capacity, respectively. Differential capacity vs. voltage plots corresponding to cycle 1 (black), cycle 2 (blue), cycle 5 (red), cycle 10 (green) and cycled 25 (dark yellow) for $\mathrm{Na}_{0.67} \mathrm{Ni}_{0.2} \mathrm{Mn}_{0.8} \mathrm{O}_{2}$ cycled at $30{ }^{\circ} \mathrm{C}$ in the voltage range (b) $1.8-3.8 \mathrm{~V}$, (c) $1.8-4.1 \mathrm{~V}$ (d) $1.8-4.4 \mathrm{~V}$ at a rate of $10 \mathrm{~mA} \mathrm{~g}^{-1}$, (e) Voltammetric analysis of $\mathrm{Na}_{0.67} \mathrm{Ni}_{0.2} \mathrm{Mn}_{0.8} \mathrm{O}_{2}$ at a scan rate of $50 \mu \mathrm{V} \mathrm{s}^{-1}$. 
To investigate the changes in oxidation states of $\mathrm{Ni}$ and $\mathrm{Mn}$ during the first cycle, $\mathrm{X}$-ray absorption spectroscopy (XAS) measurements were conducted at the Ni and Mn K-edges for the samples extracted at different states of charge (Figure 3a). Comparing the standard references $(\mathrm{NiO}$, $\mathrm{LiNiO}_{2}, \mathrm{Mn}_{2} \mathrm{O}_{3}, \mathrm{MnO}_{2}$ ) to data obtained for the as-prepared material, it is evident that the assynthesized material predominantly contains $\mathrm{Ni}^{2+}$ and $\mathrm{Mn}^{4+}$ ions. As shown in Figure 3c, Mn ions show only a minor participation in the charge compensation and essentially remain tetravalent upon charge and subsequent discharge to $3.8 \mathrm{~V}$. When the sample is further discharged to $1.8 \mathrm{~V}$ the position of the $\mathrm{Mn} \mathrm{K}$-edge spectrum shifts towards lower energy, indicating reduction to $\mathrm{Mn}^{3+}$ with a Mn valence of 3.11, calculated based on the position of the centroid of the pre-edge (Figure S3). In contrast, Ni ions contribute significantly to the charge compensation mechanism during charging (Figure 3b). After charge to $3.8 \mathrm{~V}$, the spectrum of the Ni K-edge shifts to significantly higher energy, indicating the oxidation of $\mathrm{Ni}^{2+}$. The spectrum of the sample charged to $4.1 \mathrm{~V}$ shows a minor energy shift to higher energy, representing a slight oxidation of $\mathrm{Ni}$ ions between 3.8 and 4.1 V. Interestingly, the Ni spectrum shifts towards lower energy when the sample is further charged to $4.4 \mathrm{~V}$, indicating the reduction of $\mathrm{Ni}$ ions. The reduction of transition metal cations has been previously reported in $\mathrm{Li}\left[\mathrm{Li}_{1 / 3} \mathrm{Fe}_{1 / 3} \mathrm{Sb}_{1 / 3}\right] \mathrm{O}_{2},{ }^{27} \mathrm{Li}\left[\mathrm{Li}_{1 / 3} \mathrm{Ru}_{1 / 3} \mathrm{Sn}_{1 / 3}\right] \mathrm{O}_{2}{ }^{28}$ and $\mathrm{Li}\left[\mathrm{Li}_{1 / 3} \mathrm{Mn}_{2 / 3}\right] \mathrm{O}_{2}{ }^{29}$ (square brackets represent transition metal layers) that accompanies the oxidation of neighboring oxygen anions, described as the reductive coupling mechanism. Therefore, the reduction of $\mathrm{Ni}$ observed after charging to $4.4 \mathrm{~V}$ may be an indicator of anionic charge compensation. Upon successive discharge to $3.8 \mathrm{~V}$, the Ni spectrum shifts back to higher energy, overlapping with that of the sample charged to $3.8 \mathrm{~V}$, implying reversibility of oxygen redox in agreement with the presence of oxidation and reduction peaks at ca. 4.2 and $4.1 \mathrm{~V}$, respectively, in $\mathrm{dQ} / \mathrm{dV}$ plots over several cycles (Figure 2d). At the end of discharge, Ni ions are reduced with the shifted Ni K-edge 
spectrum moving to lower energy. These results indicate that, to a large extent, the Ni cations as well as oxygen anions contribute to charge compensation in the voltage range $3.8-4.4 \mathrm{~V}$.
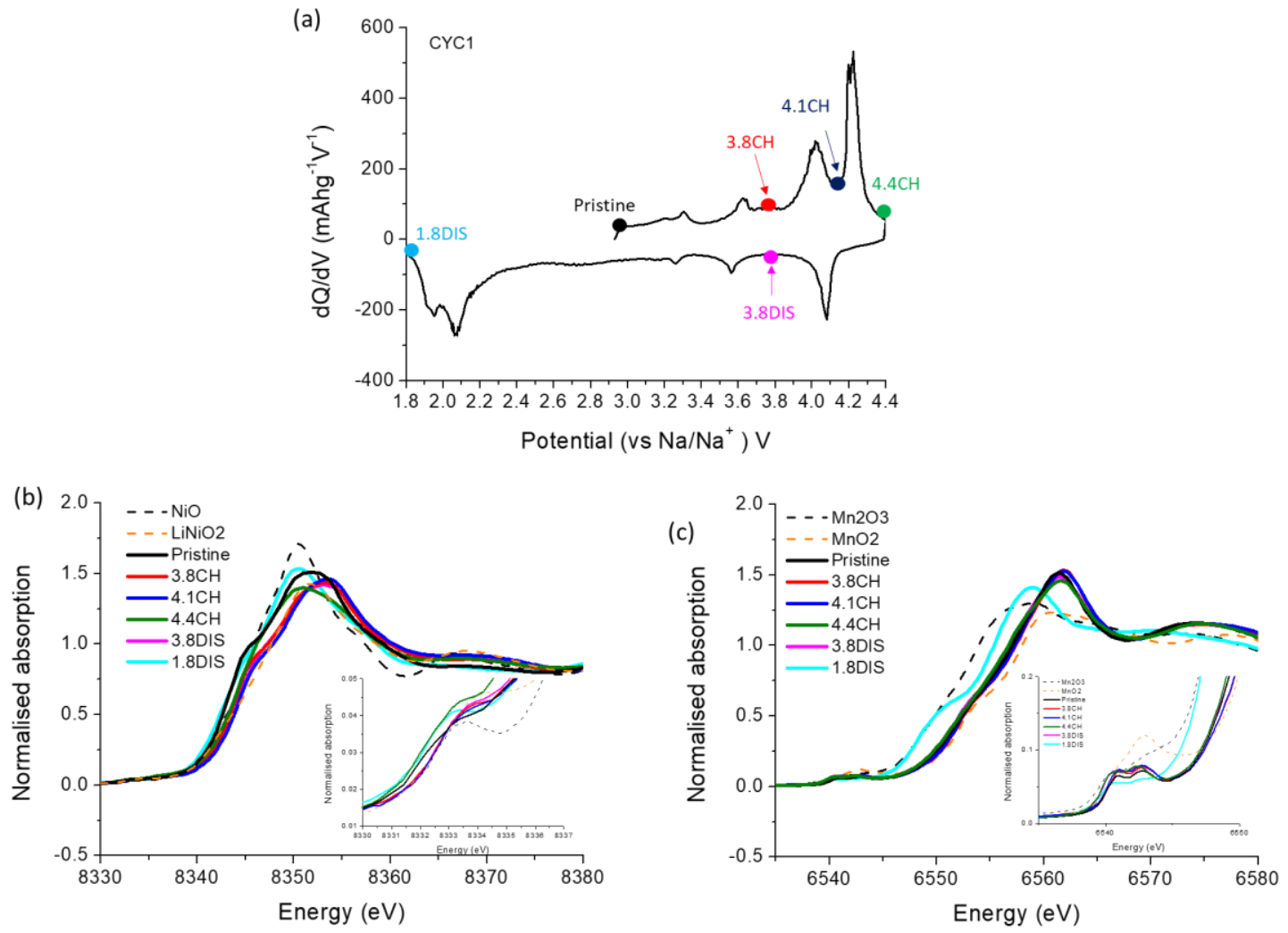

Figure 3. (a) Galvanostatic cycling curves recorded at $10 \mathrm{~mA} \mathrm{~g}^{-1}$ for $\mathrm{Na}_{0.67} \mathrm{Ni}_{0.2} \mathrm{Mn}_{0.8} \mathrm{O}_{2}$ cycled between 1.8-4.4 V with the points where XAS, SXAS, RIXS and PND measurements were conducted, (b) Ni K-edge XANES spectra of the ex-situ $\mathrm{Na}_{0.67} \mathrm{Ni}_{0.2} \mathrm{Mn}_{0.8} \mathrm{O}_{2}$ compared with reference of $\mathrm{Ni}^{2+}(\mathrm{NiO})$ and $\mathrm{Ni}^{3+}\left(\mathrm{LiNiO}_{2}\right)$ with an inset for the pre-edge and (c) Mn K-edge XANES spectra of the ex-situ $\mathrm{Na}_{0.67} \mathrm{Ni}_{0.2} \mathrm{Mn}_{0.8} \mathrm{O}_{2}$ compared with reference of $\mathrm{Mn}^{3+}\left(\mathrm{Mn}_{2} \mathrm{O}_{3}\right)$ and $\mathrm{Mn}^{4+}\left(\mathrm{MnO}_{2}\right)$ with an inset for the pre-edge.

To examine the contribution of oxygen to the redox mechanism of $\mathrm{Na}_{0.67} \mathrm{Ni}_{0.2} \mathrm{Mn}_{0.8} \mathrm{O}_{2}$, soft XAS (SXAS) spectra for the O K-edge were collected using two different detection modes: total 
fluorescence yield (TFY) and total electron yield (TEY) mode, which are sensitive to bulk (50 nm) and to surface $(2 \mathrm{~nm})$, respectively. ${ }^{30}$ Each spectrum obtained in the TFY modes (Figure 4a) can be divided into two regions. Pre-edge peaks below $535 \mathrm{eV}$ correspond to the electronic transitions from $\mathrm{O} 1 \mathrm{~s}$ states to the unoccupied $\mathrm{O} 2 \mathrm{p}$ hybridized with transition metal $3 \mathrm{~d}$ states $\left(\mathrm{TM}_{3 \mathrm{~d}}-\mathrm{O}_{2 \mathrm{p}}\right)$, whereas the broad peaks above $535 \mathrm{eV}$ are attributed to the transitions to the $\mathrm{O} 2 \mathrm{p}$ mixed with transition metal $4 \mathrm{~s}$ and $4 \mathrm{p}$ states $\left(\mathrm{TM}_{4 \mathrm{sp}}-\mathrm{O}_{2 \mathrm{p}}\right){ }^{31}$ The pre-edge features can be further distinguished by two peaks around $530 \mathrm{eV}$ and $532 \mathrm{eV}$, corresponding to the characteristic transition to the $\mathrm{O} 2 \mathrm{p}$ states hybridized with transition metal $t_{2 g}$ and $e_{g}$ states, respectively. ${ }^{6,32}$ The integrated pre-edge peak intensity between 525 and $533 \mathrm{eV}$ provides information about the metal-ligand hybridization which is highly affected not only by the nature and the oxidation state of transition metals but also by the covalent character of the $\mathrm{O} 2 \mathrm{p}$ band. ${ }^{31-33}$ In the latter case, a strong hybridization allows electrons to jump from $\mathrm{O} 2 \mathrm{p}$ to transition metal $3 \mathrm{~d}$ bands, resulting in the formation of holes in $\mathrm{O} 2 \mathrm{p}$ band..$^{28,32,34}$ The integrated intensity relative to that of the pristine sample is shown in Figure $4 \mathrm{~b}$. Three major changes in the integrated intensity during electrochemical cycling are observed: a decreased intensity for the samples charged to $3.8 \mathrm{~V}$ and $4.1 \mathrm{~V}$, a substantial increase in the intensity for the sample charged to $4.4 \mathrm{~V}$ and a decreased intensity to the level of the pristine sample at the end of discharge to $3.8 \mathrm{~V}$. The decrease appearing for $3.8 \mathrm{CH}$ and $4.1 \mathrm{CH}$ is inconsistent with the Ni K-edge X-ray absorption near edge structure (XANES) results because the oxidation of $\mathrm{Ni}$ would suggest stronger hybridization equivalent to more holes created in the O $2 p$ band. Considering the content of Mn per formula unit and possible O K-edge SXAS transitions, hybridization with $\mathrm{Mn}\left(\mathrm{Mn}_{3 \mathrm{~d}}-\mathrm{O}_{2 \mathrm{p}}\right)$ would dominate the O K-edge SXAS spectra. ${ }^{35}$ Additionally, a peak around $534 \mathrm{eV}$ found in the TFY mode may be associated with some components existing on the surface (carbonate functional group), probably caused by electrolyte 
decomposition as the peak at $534 \mathrm{eV}$ which is significantly more intense in the TEY mode (Figure S4). Electrolyte decomposition may induce the reduction of $\mathrm{Mn}$ on the surface, leading to the slight decrease in the integrated intensity for the samples charged to $3.8 \mathrm{~V}$ and $4.1 \mathrm{~V}$ as reported in Lirich oxides. ${ }^{36}$ At the end of charge, the significantly increased pre-edge intensity could indicate an increase of holes in the hybridized $\mathrm{TM}_{3 \mathrm{~d}}-\mathrm{O}_{2 \mathrm{p}}$ band because $\mathrm{Mn}$ remains tetravalent and a reduction of $\mathrm{Ni}$ is found in the $\mathrm{Mn}$ and $\mathrm{Ni}$ K-edge XANES spectra, respectively. When the sample is discharged to $3.8 \mathrm{~V}$ again, the integrated intensity returns closely to that of the pristine sample again, as would be expected for a reduction of oxygen.

In order to reveal more information about the nature of the oxygen band states during cycling, excitation energy dependent resonant inelastic X-ray scattering (RIXS) was performed. The O Kedge RIXS signal arises from the emission from the fully or partially occupied $\mathrm{O} 2 \mathrm{p}$ to the $\mathrm{O} 1 \mathrm{~s}$ states, that is sensitive to changes of the electronic structure and the chemical states of oxygen in the positive electrode material during cycling. Figure 4c shows the O K-edge RIXS spectra centered at $525 \mathrm{eV}$ emission energy for an incident energy of $530 \mathrm{eV}$. Apart from the obviously matching intensity trend, the details of the spectrum show how a sub-band seen for the $3.8 \mathrm{~V}$ charged sample at $525.5 \mathrm{eV}$ increases and shifts to higher energy for the charged samples at $4.1 \mathrm{~V}$ to $4.4 \mathrm{~V}$ forming a clear, sharp feature at about $526 \mathrm{eV}$. We also note the marked shoulder, apparently varying in intensity, at about $527 \mathrm{eV}$. We attribute the latter to a Mn d-d excitation of constant energy $\operatorname{loss}^{37}$ (see Figure S5 for complete overview of O K-RIXS spectra) that is mediated via excitation on oxygen. ${ }^{38}$ The former more interesting feature obviously is sensitive to the state of charge on cycling and we suggest an attribution to hybridized Ni $3 \mathrm{~d}-\mathrm{O} 2 \mathrm{p}$ states. This is a plausible candidate because greater electronegativity of $\mathrm{Ni}^{4+}$ than $\mathrm{Mn}^{4+}$ might favor the formation of hybridized Ni 3d-O 2p over Mn 3d-O 2p states, as well as partially filled O $2 p$ states, thanks to 
the formation of holes created during the charging process which can readily hybridize with $\mathrm{Ni} 3 \mathrm{~d}$ states. The energy position and the intensity of emission from the Ni $3 \mathrm{~d}-\mathrm{O} 2 \mathrm{p}$ hybridization is likely to be very sensitive to the number of oxygen holes created. The puzzling sharp initial drop in the pre-edge intensity of O K-edge SXAS might then be reconciled with RIXS results. The sharp drop could also be due to the contribution from the Ni 3d-O 2p hybridization, namely the transition from hybridization with fully occupied $\mathrm{O} 2 \mathrm{p}$ bands in the pristine material to hybridization with partially occupied $\mathrm{O} 2 \mathrm{p}$ bands. This behavior is also corroborated considering the observation of the differences in sharpness of the feature around the incidence energy, i.e., the elastic peak. Only the pristine material shows a distinct sharp peak whereas the spectra of the charged materials show weaker and broader structures. Let us also try to relate the above observations to previous studies on Li-rich layered oxides and P2-type sodium manganese oxides, in which both the appearance and disappearance of a peak at around $524 \mathrm{eV}$ emission energy with excitation energy about 531 $\mathrm{eV}$ and the changes in the elastic peak upon cycling have been regarded as a fingerprint of the $\mathrm{O}$ $2 p$ state changes. ${ }^{8,39-43}$ Clearly, the results of the present study show that a different route for oxygen redox processes is taken, not hitherto reported. This shows that oxygen redox processes are far from thoroughly understood and they offer opportunities and challenges for further battery development. 
(a)

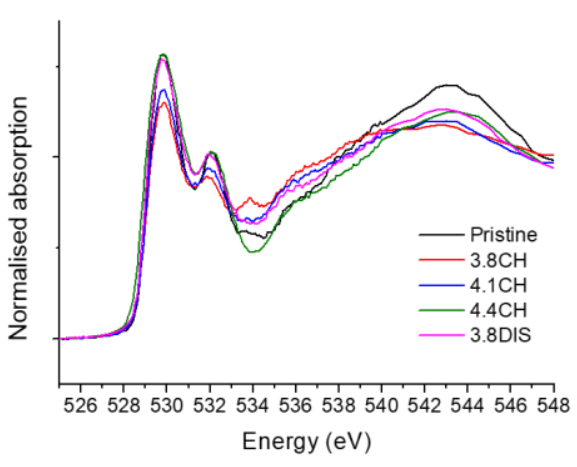

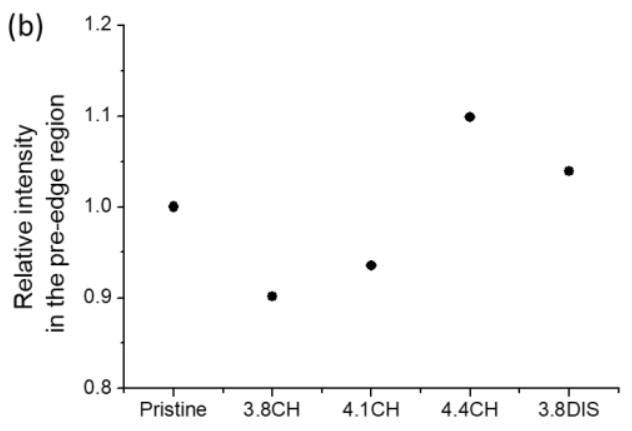

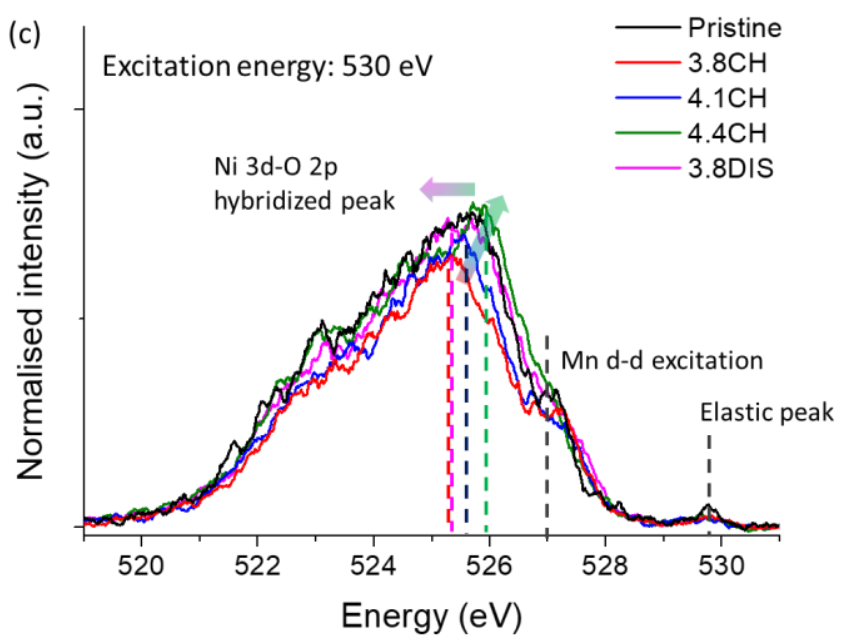

Figure 4. (a) O K-edge SXAS spectra recorded in TFY mode, (b) variation of the relative integrated intensity in the pre-edge region $(525-533 \mathrm{eV})$ for the O K-edge SXAS and (c) RIXS spectra on the O K-edge with an excitation energy of $530 \mathrm{eV}$.

\section{Conclusion}

From the electrochemical tests and the electronic structure studies using different spectroscopic techniques, it is obvious that oxygen participates in the charge compensation mechanism when $\mathrm{Na}_{0.67} \mathrm{Ni}_{0.2} \mathrm{Mnn}_{0.8} \mathrm{O}_{2}$ is charged to $4.4 \mathrm{~V}$, most strongly beyond $4.1 \mathrm{~V}$ with concomitant changes in both crystal and electronic structures. The observed oxygen redox process differs in character from that previously observed in Li-rich layered oxides with oxygen redox activity $35,39,44,45$ in that it 
does not seem to involve localized oxygen species. Instead, changes in Ni 3d-O 2p hybridization seems to play an important role. Further work is required to identify the irreversible reactions occurring between 3.8-4.1 $\mathrm{V}$, which is expected to provide strategies to improve cycling performance. 


\section{Experimental Methods}

A stoichiometric amount of sodium carbonate $\left(\mathrm{Na}_{2} \mathrm{CO}_{3}\right.$, Fisher Chemistry, $\left.\geq 99.5 \%\right)$ was dissolved in deionized water (solution A). A separate aqueous solution of nickel (II) acetate tetrahydrate $\left(\mathrm{Ni}\left(\mathrm{CH}_{3} \mathrm{CO}_{2}\right)_{2} \cdot 4 \mathrm{H}_{2} \mathrm{O}\right.$, Sigma-Aldrich, $\left.\geq 99 \%\right)$ and manganese (II) acetate tetrahydrate $\left(\mathrm{Mn}\left(\mathrm{CH}_{3} \mathrm{CO}_{2}\right)_{2} \cdot 4 \mathrm{H}_{2} \mathrm{O}\right.$, Sigma-Aldrich, $\geq 99 \%$ ) was prepared (solution B). The solution A was added dropwise to solution $\mathrm{B}$ under stirring then stirred for $10 \mathrm{~min}$. The water was removed using a rotary evaporator. The resulting solid was heated to $275^{\circ} \mathrm{C}$ for $12 \mathrm{~h}$ and cooled down to $50{ }^{\circ} \mathrm{C}$. The produced power was ground and heated again to $625^{\circ} \mathrm{C}$ for $3 \mathrm{~h}$ then quenched.

Time-of-flight PND pattern of as-synthesized P3-type $\mathrm{Na}_{0.67} \mathrm{Ni}_{0.2} \mathrm{Mn}_{0.8} \mathrm{O}_{2}$ was obtained on the GEM diffractometer at ISIS at the Rutherford Appleton Laboratory. The powder was filled in $2 \mathrm{~mm}$ quartz capillaries and sealed using vacuum grease in an Ar-filled glovebox then sealed permanently using glue under ambient atmosphere. Structures were refined by the Rietveld method using Topas Academic. ${ }^{46}$ Scanning electron microscopy (SEM) images of as-synthesized P3-type $\mathrm{Na}_{0.67} \mathrm{Ni}_{0.2} \mathrm{Mn}_{0.8} \mathrm{O}_{2}$ were recorded on a JEOL JSM-6700F. ICP-OES analysis was performed using a PerkinElmer Optima 8300 at Yonsei University. Ni and Mn K-edge XAS spectra were collected in transmission mode at the beamline B18 at the Diamond Light source. Reference spectra were collected for each measurement using $\mathrm{Ni}$ and Mn metal foils. At least three scans were taken for each sample and the data were merged, calibrated, background subtracted and normalized using the program Athena. O K-edge SXAS and RIXS spectra were recorded at the beamline BL27SU at Spring 8 in Japan. The SXAS spectra were normalized following the procedure using the program Athena i) the signal of sample was divided by the incident intensity. ii) A linear, sloping background is removed by fitting a line to the flat low energy region (from 520 to $525 \mathrm{eV}$ ) of the 
SXAS spectrum. iii) The spectrum is normalized by setting the flat low energy region to zero and the post-edge region (from 560 to $590 \mathrm{eV}$ ) to unity. ${ }^{35}$

To evaluate electrochemical performance of the materials, slurries were prepared using the active material, super C65 carbon and Solef 5130 binder in the mass ratio 75: 15: 10 in n-methyl-2pyrrolidone, which was then cast on aluminum foil using a doctor blade. After drying, $12 \mathrm{~mm}$ diameter electrode discs were punched then dried at $80^{\circ} \mathrm{C}$ under vacuum for $12 \mathrm{~h}$. For all ex-situ measurements except O K-edge SXAS and RIXS, working electrodes were constructed by mixing the active material and super $\mathrm{C} 65$ carbon in the mass ratio $75: 25$ without binder. The mixture was dried at $110^{\circ} \mathrm{C}$ under vacuum for $12 \mathrm{~h}$. CR2325 coin cells were assembled in an Ar-filled glovebox and used for evaluation of electrochemical performance. The cells consisted of a disc electrode, sodium metal as a counter/reference electrode, a glass fiber separator (Whatman, GF/F) and the electrolyte $(1 \mathrm{M} \mathrm{NaClO}$ in propylene carbonate containing $3 \%$ fluoroethylene carbonate by weight). For ex-situ O K-edge SXAS and RIXS measurements, CR2325 coin cells were assembled as described above except that Solupor membranes replaced the glass fiber separator. For all ex-situ measurements except O K-edge SXAS and RIXS, Swagelok-type cells were assembled in an Ar-filled glovebox. The cells consisted of a desired amount of working electrode, sodium metal as a counter/reference electrode, glass fiber separators (Whatman, GF/F) and the electrolyte (1M $\mathrm{NaClO}_{4}$ in propylene carbonate containing $3 \%$ fluoroethylene carbonate by weight). Galvanostatic charge/discharge cycling and voltage scans (linear sweep voltammetry) were carried out at $30{ }^{\circ} \mathrm{C}$ using a Maccor Series 4200 battery cycler.

For all ex-situ measurements, cycled cells were transferred to an Ar-filled glovebox before opening and the active material was extracted. The electrodes were rinsed carefully with dry dimethyl carbonate to remove residual electrolyte and then left under vacuum for $12 \mathrm{~h}$ to ensure all solvent 
had evaporated. XAS, SXAS, RIXS and PND measurements for cycled samples were carried out as described above. 


\title{
ASSOCIATED CONTENT
}

Supporting Information. Rietveld refinement results, O K-edge RIXS spectra

\author{
AUTHOR INFORMATION
}

\section{Corresponding Author}

*ara@st-andrews.ac.uk

\section{Author Contributions}

The manuscript was written through contributions of all authors. All authors have given approval to the final version of the manuscript.

\section{Funding Sources}

\section{ACKNOWLEDGMENT}

EJK would like to thank the Alistore ERI for the award of a studentship and Ok Sung Jeon at Yonsei University for ICP-OES measurement. The authors are grateful for the provision of beam time and assistance from instrument scientists at beamlines B18 at the Diamond Light source (as part of the Energy Materials Block Allocation Group SP14239), BL27SU at Spring 8 and GEM diffractometer at ISIS at the Rutherford Appleton Laboratory.

\section{REFERENCES}

Davies, D. M.; Verde, M. G.; Mnyshenko, O.; Chen, Y. R.; Rajeev, R.; Meng, Y. S.; Elliott, G. Combined Economic and Technological Evaluation of Battery Energy Storage for Grid Applications. Nat. Energy 2019, 4 (1), 42-50. 
Yabuuchi, N.; Kajiyama, M.; Iwatate, J.; Nishikawa, H.; Hitomi, S.; Okuyama, R.; Usui, R.; Yamada, Y.; Komaba, S. P2-Type $\mathrm{Na}_{x}\left[\mathrm{Fe}_{1 / 2} \mathrm{Mn}_{1 / 2}\right] \mathrm{O}_{2}$ Made From EarthAbundant Elements for Rechargeable Na Batteries. Nat. Mater. 2012, 11 (6), 512517.

Yabuuchi, N.; Hara, R.; Kubota, K.; Paulsen, J.; Kumakura, S.; Komaba, S. A New Electrode Material for Rechargeable Sodium Batteries: P2-Type $\mathrm{Na}_{2 / 3}\left[\mathrm{Mg}_{0.28} \mathrm{Mn}_{0.72}\right] \mathrm{O}_{2}$ with Anomalously High Reversible Capacity. J. Mater. Chem. A 2014, 2 (40), 16851-16855.

Yabuuchi, N.; Hara, R.; Kajiyama, M.; Kubota, K.; Ishigaki, T.; Hoshikawa, A.; Komaba, S. New O2/P2-Type Li-Excess Layered Manganese Oxides as Promising Multi-Functional Electrode Materials for Rechargeable Li/Na Batteries. Adv. Energy Mater. 2014, 4 (13), 1301453-1301476. la Llave, de, E.; Talaie, E.; Levi, E.; Nayak, P. K.; Dixit, M.; Rao, P. T.; Hartmann, P.; Chesneau, F.; Major, D. T.; Greenstein, M.; Aurbach, D.; Nazar, L. F. Improving Energy Density and Structural Stability of Manganese Oxide Cathodes for Na-Ion Batteries by Structural Lithium Substitution. Chem. Mater. 2016, 28 (24), 9064-9076. Ma, C.; Alvarado, J.; Xu, J.; Clément, R. J.; Kodur, M.; Tong, W.; Grey, C. P.; Meng, Y. S. Exploring Oxygen Activity in the High Energy P2-Type $\mathrm{Na}_{0.78} \mathrm{Ni}_{0.23} \mathrm{Mn}_{0.69} \mathrm{O}_{2}$ Cathode Material for Na-Ion Batteries. J. Am. Chem. Soc. 2017, 139 (13), 4835-4845. Bai, X.; Sathiya, M.; Sánchez, B. M.; Iadecola, A.; Vergnet, J.; Dedryvère, R.; Saubanère, M.; Abakumov, A. M.; Rozier, P.; Tarascon, J.-M. Anionic Redox Activity in a Newly Zn-Doped Sodium Layered Oxide P2-Na2/3 $\mathrm{Mn}_{1-y} \mathrm{Zn}_{\mathrm{y}} \mathrm{O}_{2}$ $(0<\mathrm{y}<0.23)$. Adv. Energy Mater. 2018, 8 (32), 1802379-1802391. 
Maitra, U.; House, R. A.; Somerville, J. W.; Tapia-Ruiz, N.; Lozano, J. G.; Guerrini, N.; Hao, R.; Luo, K.; Jin, L.; Pérez-Osorio, M. A.; Massel, F.; Pickup, D. M.; Ramos, S.; Lu, X.; McNally, D. E.; Chadwick, A. V.; Giustino, F.; Schmitt, T.; Duda, L. C.; Roberts, M. R.; Bruce, P. G. Oxygen Redox Chemistry Without Excess Alkali-Metal Ions in $\mathrm{Na}_{2 / 3}\left[\mathrm{Mg}_{0.28} \mathrm{Mn}_{0.72}\right] \mathrm{O}_{2}$. Nat. Chem. 2018, 10 (3), 288-295.

Du, K.; Zhu, J.; Hu, G.; Gao, H.; Li, Y.; Goodenough, J. B. Exploring Reversible Oxidation of Oxygen in a Manganese Oxide. Energy Environ. Sci. 2016, 9 (8), 25752577.

(10) Rong, X.; Hu, E.; Liu, J.; Liu, Y.; Wang, Y.; Wu, J.; Yu, X.; Page, K.; Hu, Y.-S.; Yang, W.; Li, H.; Yang, X.-Q.; Chen, L.; Huang, X. Structure-Induced Reversible Anionic Redox Activity in Na Layered Oxide Cathode. Joule 2018, 2 (1), 125-140.

(11) Song, B.; Hu, E.; Liu, J.; Zhang, Y.; Yang, X.-Q.; Nanda, J.; Huq, A.; Page, K. A Novel P3-Type $\mathrm{Na}_{2 / 3} \mathrm{Mg}_{1 / 3} \mathrm{Mn}_{2 / 3} \mathrm{O}_{2}$ as High Capacity Sodium-Ion Cathode Using Reversible Oxygen Redox. J. Mater. Chem. A 2019, 7 (4), 1491-1498.

de Boisse, B. M.; Nishimura, S.-I.; Watanabe, E.; Lander, L.; Tsuchimoto, A.; Kikkawa, J.; Kobayashi, E.; Asakura, D.; Okubo, M.; Yamada, A. Highly Reversible Oxygen-Redox Chemistry at $4.1 \mathrm{v}$ in $\mathrm{Na}_{4 / 7-\mathrm{X}}\left[\square_{1 / 7} \mathrm{Mn}_{6 / 7}\right] \mathrm{O}_{2}$ ( $\square$ : Mn Vacancy). $A d v$. Energy Mater.2018, 8 (20), 1800409-1800416. Li, Y.; Wang, X.; Gao, Y.; Zhang, Q.; Tan, G.; Kong, Q.; Bak, S.; Lu, G.; Yang, X.Q.; Gu, L.; Lu, J.; Amine, K.; Wang, Z.; Chen, L. Native Vacancy Enhanced Oxygen Redox Reversibility and Structural Robustness. Adv. Energy Mater. 2018, 9 (4), 1803087-1803098.

(14) Grimaud, A.; Hong, W. T.; Shao-Horn, Y.; Tarascon, J.-M. Anionic Redox Processes 
for Electrochemical Devices. Nat. Mater. 2016, 15 (2), 121-126.

Billaud, J.; Singh, G.; Armstrong, A. R.; Gonzalo, E.; Roddatis, V.; Armand, M.;

Rojo, T.; Bruce, P. G. Na ${ }_{0.67} \mathrm{Mn}_{1-\mathrm{x}} \mathrm{Mg}_{\mathrm{x}} \mathrm{O}_{2}(0 \leq \mathrm{x} \leq 0.2)$ : a High Capacity Cathode for Sodium-Ion Batteries. Energy Environ. Sci. 2014, 7 (4), 1387-1391.

(16) Lu, Z.; Dahn, J. R. In Situ X-Ray Diffraction Study of P $2-\mathrm{Na}_{2 / 3}\left[\mathrm{Ni}_{1 / 3} \mathrm{Mn}_{2 / 3}\right] \mathrm{O}_{2} . J$. Electrochem. Soc. 2001, 148 (11), A1225-A1229.

Wang, H.; Yang, B.; Liao, X.-Z.; Xu, J.; Yang, D.; He, Y.-S.; Ma, Z.-F. Electrochemical Properties of P2-Na $2 / 3\left[\mathrm{Ni}_{1 / 3} \mathrm{Mn}_{2 / 3}\right] \mathrm{O}_{2}$ Cathode Material for Sodium Ion Batteries When Cycled in Different Voltage Ranges. Electrochim. Acta 2013, 113, 200-204.

(18) Lee, D. H.; Xu, J.; Meng, Y. S. An Advanced Cathode for Na-Ion Batteries with High Rate and Excellent Structural Stability. Phys. Chem. Chem. Phys. 2013, 15 (9), 33043312.

(19) Xu, J.; Lee, D. H.; Clément, R. J.; Yu, X.; Leskes, M.; Pell, A. J.; Pintacuda, G.; Yang, X.-Q.; Grey, C. P.; Meng, Y. S. Identifying the Critical Role of Li Substitution in P2$\mathrm{Na}_{\mathrm{x}}\left[\mathrm{Li}_{\mathrm{y}} \mathrm{Ni}_{\mathrm{z}} \mathrm{Mn}_{1-\mathrm{y}-\mathrm{z}}\right] \mathrm{O}_{2}(0<\mathrm{x}, \mathrm{y}, \mathrm{z}<1)$ Intercalation Cathode Materials for HighEnergy Na-Ion Batteries. Chem. Mater. 2013, 26 (2), 1260-1269.

(20) Hou, H.; Gan, B.; Gong, Y.; Chen, N.; Sun, C. P2-Type Na0.67Ni $\mathrm{Ni}_{0.23} \mathrm{Mg}_{0.1} \mathrm{Mn}_{0.67} \mathrm{O}_{2}$ as a High-Performance Cathode for a Sodium-Ion Battery. Inorg. Chem. 2016, 55 (17), 9033-9037.

(21) Wang, P.-F.; You, Y.; Yin, Y.-X.; Wang, Y.-S.; Wan, L.-J.; Gu, L.; Guo, Y.-G. Suppressing the P2-O2 Phase Transition of $\mathrm{Na}_{0.67} \mathrm{Mn}_{0.67} \mathrm{Ni}_{0.33} \mathrm{O}_{2}$ by Magnesium Substitution for Improved Sodium-Ion Batteries. Angew. Chem. Int. Ed 2016, 55 (26), 
$7445-7449$.

(22) Singh, G.; Tapia-Ruiz, N.; Lopez del Amo, J. M.; Maitra, U.; Somerville, J. W.; Armstrong, A. R.; Martinez de Ilarduya, J.; Rojo, T.; Bruce, P. G. High Voltage MgDoped $\mathrm{Na}_{0.67} \mathrm{Ni}_{0.3-\mathrm{x}} \mathrm{Mg}_{\mathrm{x}} \mathrm{Mn}_{0.7} \mathrm{O}_{2}(\mathrm{x}=0.05,0.1)$ Na-Ion Cathodes with Enhanced Stability and Rate Capability. Chem. Mater. 2016, 28 (14), 5087-5094.

Tapia-Ruiz, N.; Dose, W. M.; Sharma, N.; Chen, H.; Heath, J.; Somerville, J. W.; Maitra, U.; Islam, M. S.; Bruce, P. G. High Voltage Structural Evolution and Enhanced Na-Ion Diffusion in $\mathrm{P} 2-\mathrm{Na}_{2 / 3} \mathrm{Ni}_{1 / 3-\mathrm{x}} \mathrm{Mg}_{\mathrm{x}} \mathrm{Mn}_{2 / 3} \mathrm{O}_{2}(0 \leq \mathrm{x} \leq 0.2)$ Cathodes From Diffraction, Electrochemical and Ab Initiostudies. Energy Environ. Sci. 2018, $11(6), 1470-1479$.

Kalapsazova, M.; Ortiz, G. F.; Tirado, J. L.; Dolotko, O.; Zhecheva, E.; Nihtianova, D.; Mihaylov, L.; Stoyanova, R. P3-Type Layered Sodium-Deficient NickelManganese Oxides: a Flexible Structural Matrix for Reversible Sodium and Lithium Intercalation. ChemPlusChem 2015, 80 (11), 1642-1656. Ma, J.; Bo, S.-H.; Wu, L.; Zhu, Y.; Grey, C. P.; Khalifah, P. G. Ordered and Disordered Polymorphs of $\mathrm{Na}\left(\mathrm{Ni}_{2 / 3} \mathrm{Sb}_{1 / 3}\right) \mathrm{O}_{2}$ : Honeycomb-Ordered Cathodes for NaIon Batteries. Chem. Mater. 2015, 27 (7), 2387-2399.

(26) Yoshida, H.; Yabuuchi, N.; Kubota, K.; Ikeuchi, I.; Garsuch, A.; Schulz-Dobrick, M.; Komaba, S. P2-Type $\mathrm{Na}_{2 / 3} \mathrm{Ni}_{1 / 3} \mathrm{Mn}_{2 / 3-\mathrm{x}} \mathrm{Ti}_{\mathrm{x}} \mathrm{O}_{2}$ as a New Positive Electrode for Higher Energy Na-Ion Batteries. Chem. Commun. 2014, 50 (28), 3677-3680.

(27) McCalla, E.; Sougrati, M. T.; Rousse, G.; Berg, E. J.; Abakumov, A.; Recham, N.; Ramesha, K.; Sathiya, M.; Dominko, R.; Van Tendeloo, G.; Novák, P.; Tarascon, J.M. Understanding the Roles of Anionic Redox and Oxygen Release During 
Electrochemical Cycling of Lithium-Rich Layered $\mathrm{Li}_{4} \mathrm{FeSbO}_{6}$. J. Am. Chem. Soc. 2015, 137 (14), 4804-4814.

Sathiya, M.; Rousse, G.; Ramesha, K.; Laisa, C. P.; Vezin, H.; Sougrati, M. T.; Doublet, M.-L.; Foix, D.; Gonbeau, D.; Walker, W.; Prakash, A. S.; Ben Hassine, M.; Dupont, L.; Tarascon, J.-M. Reversible Anionic Redox Chemistry in High-Capacity Layered-Oxide Electrodes. Nat. Mater. 2013, 12 (9), 827-835.

Oishi, M.; Yamanaka, K.; Watanabe, I.; Shimoda, K.; Matsunaga, T.; Arai, H.; Ukyo, Y.; Uchimoto, Y.; Ogumi, Z.; Ohta, T. Direct Observation of Reversible Oxygen Anion Redox Reaction in Li-Rich Manganese Oxide, $\mathrm{Li}_{2} \mathrm{MnO}_{3}$, Studied by Soft XRay Absorption Spectroscopy. J. Mater. Chem. A 2016, 4 (23), 9293-9302.

(30) de Groot, F. M. F. X-Ray Absorption and Dichroism of Transition Metals and Their Compounds. J. Electron Spectrosc. 1994, 67 (4), 529-622.

de Groot, F. M. F.; Grioni, M.; Fuggle, J. C.; Ghijsen, J.; Sawatzky, G. A.; Petersen, H. Oxygen 1s X-Ray-Absorption Edges of Transition-Metal Oxides. Phys. Rev. B 1989, $40(8), 5715-5723$.

Hy, S.; Cheng, J.-H.; Liu, J.-Y.; Pan, C.-J.; Rick, J.; Lee, J.-F.; Chen, J.-M.; Hwang, B.-J. Understanding the Role of Ni in Stabilizing the Lithium-Rich High-Capacity Cathode Material $\mathrm{Li}\left[\mathrm{Ni}_{\mathrm{x}} \mathrm{Li}_{(1-2 \mathrm{x}) / 3} \mathrm{Mn}_{(2-\mathrm{x}) / 3}\right] \mathrm{O}_{2}(0 \leq \mathrm{x} \leq 0.5)$. Chem. Mater. 2014, 26 (24), 6919-6927. Yoon, W.-S.; Balasubramanian, M.; Chung, K. Y.; Yang, X.-Q.; McBreen, J.; Grey, C. P.; Fischer, D. A. Investigation of the Charge Compensation Mechanism on the Electrochemically Li-Ion Deintercalated $\mathrm{Li}_{1-x} \mathrm{Co}_{1 / 3} \mathrm{Ni}_{1 / 3} \mathrm{Mn}_{1 / 3} \mathrm{O}_{2}$ Electrode System by Combination of Soft and Hard X-Ray Absorption Spectroscopy. J. Am. Chem. Soc. 
2005, 127 (49), 17479-17487.

(34) Rouxel, J. Anion-Cation Redox Competition and the Formation of New Compounds in Highly Covalent Systems. Chem.: Eur. J. 1996, 2 (9), 1053-1059.

Luo, K.; Roberts, M. R.; Hao, R.; Guerrini, N.; Pickup, D. M.; Liu, Y.-S.; Edström, K.; Guo, J.; Chadwick, A. V.; Duda, L. C.; Bruce, P. G. Charge-Compensation in 3dTransition-Metal-Oxide Intercalation Cathodes Through the Generation of Localized Electron Holes on Oxygen. Nat. Chem. 2016, 8 (7), 684-691.

(39) Xu, J.; Sun, M.; Qiao, R.; Renfrew, S. E.; Ma, L.; Wu, T.; Hwang, S.; Nordlund, D.; Su, D.; Amine, K.; Lu, J.; McCloskey, B. D.; Yang, W.; Tong, W. Elucidating Anionic Oxygen Activity in Lithium-Rich Layered Oxides. Nat. Commun. 2018, 9 (1), 947957.

(40) Gent, W. E.; Lim, K.; Liang, Y.; Li, Q.; Barnes, T.; Ahn, S.-J.; Stone, K. H.; McIntire, 
M.; Hong, J.; Song, J. H.; Li, Y.; Mehta, A.; Ermon, S.; Tyliszczak, T.; Kilcoyne, D.; Vine, D.; Park, J.-H.; Doo, S.-K.; Toney, M. F.; Yang, W.; Prendergast, D.; Chueh, W. C. Coupling Between Oxygen Redox and Cation Migration Explains Unusual Electrochemistry in Lithium-Rich Layered Oxides. Nat. Commun. 2017, 8 (1), 1-12. Electrodes. ACS Appl. Mater. Interfaces 2017, 9 (42), 36463-36472.

Dai, K.; Wu, J.; Zhuo, Z.; Li, Q.; Sallis, S.; Mao, J.; Ai, G.; Sun, C.; Li, Z.; Gent, W. E.; Chueh, W. C.; Chuang, Y.-D.; Zeng, R.; Shen, Z.-X.; Pan, F.; Yan, S.; Piper, L. F. J.; Hussain, Z.; Liu, G.; Yang, W. High Reversibility of Lattice Oxygen Redox Quantified by Direct Bulk Probes of Both Anionic and Cationic Redox Reactions. Joule 2019, 3 (2), 518-541.

Ma, L. A.; Massel, F.; Naylor, A. J.; Duda, L. C.; Younesi, R. Understanding Charge Compensation Mechanisms in $\mathrm{Na}_{0.56} \mathrm{Mg}_{0.04} \mathrm{Ni}_{0.19} \mathrm{Mn}_{0.70} \mathrm{O}_{2}$. Commun. Chem. 2019, 2 (1), 510-519.

Wu, J.; Li, Q.; Sallis, S.; Zhuo, Z.; Gent, W. E.; Chueh, W. C.; Yan, S.; Chuang, Y.D.; Yang, W. Fingerprint Oxygen Redox Reactions in Batteries Through HighEfficiency Mapping of Resonant Inelastic X-Ray Scattering. Condens. Matter. 2019, $4,1-12$.

Luo, K.; Roberts, M. R.; Guerrini, N.; Tapia-Ruiz, N.; Hao, R.; Massel, F.; Pickup, D. M.; Ramos, S.; Liu, Y.-S.; Guo, J.; Chadwick, A. V.; Duda, L. C.; Bruce, P. G. Anion Redox Chemistry in the Cobalt Free 3d Transition Metal Oxide Intercalation Electrode $\mathrm{Li}\left[\mathrm{Li}_{0.2} \mathrm{Ni}_{0.2} \mathrm{Mn}_{0.6}\right] \mathrm{O}_{2}$. J. Am. Chem. Soc. 2016, 138 (35), 11211-11218.

(46) Coelho, A. A. Whole-Profile Structure Solution From Powder Diffraction Data Using 
Simulated Annealing. J. Appl. Crystallogr. 2000, 33 (3), 899-908. 